Schulich School of Law, Dalhousie University

Schulich Law Scholars

Research Papers, Working Papers, Conference

Papers

Faculty Scholarship

$10-17-2014$

\title{
Achieving National Altruistic Self-Sufficiency in Human Eggs for Third-Party Reproduction in Canada
}

Jocelyn Downie

Dalhousie University - Schulich School of Law, jocelyn.downie@dal.ca

Francoise Baylis

Dalhousie University, francoise.baylis@dal.ca

Follow this and additional works at: https://digitalcommons.schulichlaw.dal.ca/working_papers

\section{Recommended Citation}

Downie, Jocelyn and Baylis, Francoise, "Achieving National Altruistic Self-Sufficiency in Human Eggs for Third-Party Reproduction in Canada" (2014). Research Papers, Working Papers, Conference Papers. 5. https://digitalcommons.schulichlaw.dal.ca/working_papers/5

This Working Paper is brought to you for free and open access by the Faculty Scholarship at Schulich Law Scholars. It has been accepted for inclusion in Research Papers, Working Papers, Conference Papers by an authorized administrator of Schulich Law Scholars. For more information, please contact hannah.steeves@dal.ca. 


\title{
ACHIEVING NATIONAL ALTRUISTIC SELF-SUFFICIENCY IN HUMAN EGGS FOR THIRD-PARTY REPRODUCTION IN CANADA
}

FRANCOISE BAYLIS AND JOCELYN DOWNIE

\begin{abstract}
To avoid the commercialization of reproduction, the Canadian Assisted Human Reproduction Act (AHR Act 2004) prohibits the purchase of human eggs. We endorse this legal prohibition and moreover believe that this facet of the law should not be allowed to have as an unintended consequence an increase in transnational trade in human eggs. In an effort to avoid this consequence, and to be consistent with the AHR Act, we advocate a system of national altruistic self-sufficiency. This article briefly outlines a number of strategies to increase the domestic altruistic supply of third-party eggs and decrease the domestic demand for third-party eggs.
\end{abstract}

\section{Introduction}

In Canada, the use of reproductive technologies is largely governed by the Assisted Human Reproduction Act (AHR Act 2004). One of the founding principles of the AHR Act is that "trade in the reproductive capabilities of women and men, and the exploitation of children, women and men for commercial ends raise health and ethical concerns that justify their prohibition" (AHR Act 2004, s. 2(f)). This principle is instantiated in several sections of the $A H R$ Act, including s. 7 which prohibits the purchase of gametes. It follows that, in Canada, the legal supply of human eggs (fresh or frozen) is limited to eggs from donors. ${ }^{1}$

Donors, by definition, are women who do not receive payment for their eggs. Typically, 
known donors are the close friends, sisters, cousins or relatives of women without healthy eggs (e.g., women at risk of having children with a debilitating genetic condition, women with gonadal dysfunction (non-working ovaries), women who have had cancer treatment without fertility preservation, and women who have gone through (premature) menopause. More generally, these egg donors are "well-educated, partnered or married, employed, have their own children and are of middle class socio-economics status" (Yee, Hitkari, and Greenblatt 2007, 2046). They are women venturing into a joint project to help a friend or family member conceive a child (Yee, Hitkari, and Greenblatt 2007, 2048). The profile of anonymous donors is somewhat different. These donors are women who, for personal reasons, are motivated to make a gift of their eggs to help strangers achieve their goal of having a family using third-party eggs.

There are few known or anonymous egg donors in Canada and this is largely because of the onerous, invasive and risky nature of egg production. As we summarize elsewhere:

The daily hormone injections can be painful and uncomfortable, causing cramping, abdominal pain, nausea, vomiting, bloating, mood changes, and irritability. More serious potential harms include rapid weight gain and respiratory difficulty, damage to the organs that are close to the ovaries (e.g., bladder, bowel, uterus), decreased fertility, infertility, and life-threatening hemorrhage, thromboembolism, and ovarian, breast, or colon cancer. Potential psychological harms include significant stress and its sequelae (Downie and Baylis 2013, 224).

Lack of enthusiasm for egg production and donation among healthy volunteers, in Canada and elsewhere, is nothing new. More than twenty years ago clinicians commented on how difficult it was to find women to donate their eggs to others (family members, friends or 
strangers) owing, in part, to the medical risks (Kolata 1991). Medical risks noted at that time included the risk of hemorrhage and infection, the risk of damage to reproductive organs, and potential infertility. Dr. Richard Dickey, then at the Fertility Institute of New Orleans, in what may have been an unguarded moment, went so far as to say "I guarantee that some of these donors are going to have reproductive problems in the future" (Liebmann-Smith 1992, 126).

With time and experience, psychological risks with third-party reproduction have also been reported retrospectively by egg providers. They identify the following risks:

[S]ense of loss and emotional attachment to eggs and/or children born as a result of the donation; regret/mental anguish; depression/sadness; uneasiness about the possibility of a child "out there" with donor's DNA; feeling that resultant child(ren) should have relationship with his/her genetic mother; curiosity about the end result of the donation and any possible resultant child(ren); risk that a resulting child might later seek out donor or that donor would want to locate child; mood swings; desire to back out of donation agreement when time came to harvest eggs; and stress related to donation procedures. (Kenney and McGowan 2010, 461)

Because, without payment, few women would be willing to incur the medical and psychological risks (not to mention the inconvenience and discomfort) of controlled ovarian hyperstimulation and egg retrieval to provide eggs for others, human eggs acquired a price in the market place. In the early 1990s, the average price was 2,000 USD per cycle (Liebmann-Smith 1992, 124). By 2004, at which time the prohibition on purchasing human eggs came into force in Canada, the average price was closer to 5,000 USD per cycle. It has been suggested that the prohibition on purchasing human eggs in Canada is responsible for a decrease in the supply of eggs within Canada to meet the domestic demand for third-party reproduction. This may or may 
not be true. What we do know is that there has been an increase in the number of Canadians who buy human eggs abroad, making transnational trade in human eggs a direct (albeit unintended) consequence of the AHR Act (Yee, Hitkari, and Greenblatt 2007; Downie and Baylis 2013).

Some Canadians travel to purchase fresh eggs, and many of them make their purchases south of the border in the United States where there is a largely unregulated commercial market in human eggs. Although in 2007 the American Society for Reproductive Medicine (ASRM) issued compensation guidelines suggesting that "[t] otal payments to donors in excess of 5,000 USD require justification and sums above 10,000 USD are not appropriate" (Ethics Committee 2007, 305), agencies and individuals routinely negotiate higher compensation, sometimes in excess of 10,000 USD (Levine 2010). Other known destinations for Canadians purchasing eggs are Latin America, Europe, and India/Asia (Hughes and DeJean 2010). As well, a survey of fertility patients and potential fertility patients identifies the Czech Republic, India and Mexico as destination countries for Canadians (Blyth 2010). Payments range from several hundred dollars in some countries to tens of thousands of dollars in others (Pennings et al. 2014; Ethics Committee 2007).

Other Canadians prefer to stay at home and either pay for egg providers to travel to Canada for a fresh cycle (Motluk 2013), or pay for imported frozen eggs from US-based agencies who will ship directly to fertility clinics in Canada. Among these agencies is the World Egg Bank. The cost is quoted "per cycle" at 16,500 USD for 6 mature frozen eggs, 17,500 USD for 7 mature frozen eggs and another 2,750 USD for each additional frozen egg (World Egg Bank 2014).

Elsewhere we have argued that the legally and morally suspect commercial trade in human eggs between Canadian buyers and international sellers (individuals and agencies) is 
deeply problematic. In Transnational Trade in Human Eggs: Law, Policy and (In)Action in Canada, we explain in considerable detail the legal prohibition on purchasing human eggs in Canada and describe efforts by Canadians to circumvent this domestic prohibition by engaging in cross-border transactions. We then lament the failure of responsible parties (including most prominently Health Canada - the federal agency responsible for compliance, enforcement and outreach in relation to the AHR Act) to enforce the AHR Act. That article ends with a call for national self-sufficiency in a manner that would be consistent with the AHR Act (i.e., altruistic) (Downie and Baylis 2013). This current article extends the discussion, with a particular focus on strategies to increase the domestic supply of third-party eggs as well as strategies to decrease the domestic demand for third-party eggs.

\section{Self-sufficiency in human eggs for third-party reproduction}

Our support for self-sufficiency in human eggs for third-party reproduction in Canada is predicated on two things: (i) our acceptance of third-party reproduction; and (ii) our firm endorsement of the Canadian prohibition on the purchase of human eggs, as entrenched in the AHR Act and affirmed in the AHR Reference. ${ }^{2}$

\section{a. History}

Self-sufficiency first surfaced as a concept in the health (as opposed to economic) policy arena in discussions about the need for a safe, secure and sufficient supply of human blood and blood products (Martin 2010, 385). In that context, self-sufficiency was (and continues to be) defined as "the provision of blood and blood products from within a population to satisfy the clinical needs of that population" (van Aken 1992, 22). On this definition, it is evident that the 
pursuit of self-sufficiency in blood and blood products is about meeting needs and these needs are to be met from within - that is, the needs of individuals in a particular community are to be met by individuals in that same community. Also evident with this definition is the fact that the concept of self-sufficiency does not in itself include a commitment to altruism. On safety and moral grounds, however, the proponents of self-sufficiency in blood and blood products maintain a steadfast commitment to meeting needs through voluntary, non-remunerated donation. The objective in promoting self-sufficiency in blood and blood products is not to create a local market for these human biological materials, but rather to create a safe, non-exploitative domestic supply of these biological materials in order to meet local need (Keown 1997).

More recently, the concept of self-sufficiency has been applied to human biological materials including solid organs, human eggs and stem cells. According to Dominique Martin "[s]elf-sufficiency in HBM [human biological materials] is the achievement by a population of an adequate supply of HBM and healthcare services, such that the needs of the population for therapeutic procedures involving these materials may be met using their own resources" (Martin 2010). And more recently, G.D.K. Crozier and Martin have described the pursuit of selfsufficiency with specific reference to "the adoption of policies designed to achieve a supply of such [human biological materials] sufficient to meet community needs using domestic resources" (Crozier and Martin 2012, 48).

Here once again we see the commitment to meeting the needs of populations from within, but a shift occurs with respect to the role of altruism. Whereas the original commitment to selfsufficiency in the context of blood and blood products saw altruism adopted for reasons of safety and morality, it appears that altruism is now seen as a necessary condition for the realization of self-sufficiency. Martin writes: “[c]ommercial donation would surely result in an inequitable 
distribution of the burden of donation on the poor and undermine the principles of reciprocity and solidarity on which self-sufficiency depends" (emphasis added; Martin 2010, 386). And more recently, Crozier and Martin write: "By adopting a non-commercial approach to FRR, [female reproductive resources] it is expected that the evolution of societal attitudes towards infertility and donation of FRR will result in increased public support for participation in donation programs and hence higher rates of donation" (Crozier and Martin 2012, 48). Here again altruism is not an intrinsic feature of self-sufficiency, though there are seen to be good reasons to embrace altruism - reasons of safety, morality or efficacy.

In brief, self-sufficiency in the context of health has two important and distinct features. The first of these features derives from the term sufficiency and speaks to the commitment to developing and adopting solutions to problems of insufficient supply. The second feature derives from the qualifying term self, and speaks to a particular locus of responsibility for the sufficiency - problems of insufficiency within a community or a population are to be addressed using the resources of that community or population.

\section{b. Need}

As noted above, self-sufficiency in the context of health care has been defined in terms of clinical need. This is not surprising as the concept was first used in a health context with reference to the insufficient supply of blood and blood products required for life-saving interventions. There was no dispute over whether this insufficient supply reflected actual clinical need and no questioning of the desire to meet clinical need. While it is easy to both understand and endorse the reference to clinical needs within a population with respect to life-saving human biological materials, it is much less clear that this is an appropriate approach to human eggs for 
third-party reproduction. Indeed, there is reason to question the use of the term 'need' with reference to self-sufficiency in human eggs. Martin and Crozier recognize this challenge with respect to social infertility (i.e., infertility resulting from sexual or social preferences, natural ageing, and delayed reproduction) and allow that some will not see the desire for eggs for reasons of social infertility as constituting a 'need' (Martin 2010, 387; Crozier and Martin 2012, 49). For our part, we believe the challenge applies equally to medical infertility and we are deeply concerned about the construction of need in the context of assisted human reproduction.

Does (social or medical) infertility create a 'clinical need', a 'need of the population', or a 'community need' for third-party eggs? What constitutes a 'need' and how is this different from a 'want' or a 'desire'? Should society only promote self-sufficiency in relation to a 'need' or also in relation to a 'want' or a 'desire'? We do not attempt to address these important questions here because, as noted earlier, in this article we are working within the context of the AHR Act. This Act does not distinguish between needs, wants and desires - rather it allows for the meeting of all demands for eggs within limits (that have nothing to do with drawing distinctions between needs, wants and desires). For the purposes of this discussion, therefore, self-sufficiency is not coupled with the satisfaction of a 'need'; in our analysis we replace 'need' with 'demand' (a term that includes needs, wants and desires). ${ }^{3}$

\section{c. 'Supply' and 'demand'}

In our discussion of self-sufficiency in human eggs, we use the term 'supply' as a proxy for the amount of human eggs that are available for third-party reproduction and the term 'demand' as a proxy for the needs, wants or desires of intended parents for access to eggs for third-party reproduction. We do not thereby import from microeconomics the concept of 'supply 
and demand' that is used to explain price changes in the market. Consistent with the AHR Act and the Supreme Court of Canada decision in Reference re Assisted Human Reproduction Act (AHR Reference 2010), we do not endorse the market as a legitimate way to approach issues in assisted human reproduction. We use the terms 'supply' and 'demand' only insofar as we acknowledge that sufficiency requires an equilibrium between 'supply' and 'demand'.

\section{d. National and altruistic}

Along with others, we recognize that self-sufficiency aims to address problems of insufficiency within a community or population using the resources of that community or population. Hereafter, we make explicit reference to national self-sufficiency. We focus on national instead of provincial/territorial self-sufficiency because the AHR Act operates at a federal level. As well, we focus on national instead of international self-sufficiency because, as noted earlier, we are concerned about exporting commercialization that is not permitted within Canada.

Secondly, we recognize that self-sufficiency is not inherently limited to altruistic supply. In recognition of this feature of self-sufficiency, we explicitly focus our discussion on altruistic national self-sufficiency, consistent with the AHR Act which prohibits the commercialization of eggs.

Our primary objective in promoting national altruistic self-sufficiency in human eggs for third-party reproduction is to reduce (if not eliminate) the outsourcing of activities that involve the commercialization of reproductive materials. In this way, our argument in support of selfsufficiency in human eggs differs from established norms in promoting self-sufficiency - the primary concern is not with reducing dependency on foreign sources of human reproductive 
materials, but with reducing (eliminating) the commercialization of human reproductive materials. ${ }^{4}$ That is, our commitment to national altruistic self-sufficiency in human eggs for third-party reproduction is motivated by the belief that one doesn't protect the Canadian public from "practices that may contravene morality" (AHR Reference 2010, para 21) or "may undermine fundamental moral precepts" (AHR Reference 2010, para 23) by prohibiting the sale of human eggs, but then fail to prohibit participation in transnational trade thereby allowing Canadians to export the commercialization of reproduction to other countries.

We now turn our attention to a number of strategies that, pursued in concert, could contribute to the realization of national altruistic self-sufficiency. Strategies to increase the domestic supply of third-party eggs (in accordance with the AHR Act) include: clarity regarding legally permissible reimbursements for egg donors; changes in the law with respect to legal parentage to protect the interests of egg donors; the introduction of professional guidelines to protect and promote the health and well-being of egg donors; attention to the concerns of experienced egg donors; and targeted educational campaigns on the benefits of altruistic egg donation. Strategies to decrease the demand for domestic and foreign third-party eggs include: programs and policies to prevent some types of social infertility as well as programs and policies to prevent (and, where possible, treat) medical infertility; support for child-free living as well as support for alternative ways of family making (for example, adoption); public awareness campaigns on the harms of transitional trade in eggs; and a firm commitment to enforcement of the AHR Act prohibition on the purchase of eggs. 


\section{Increasing the domestic supply of human eggs for third-party reproduction}

A logical first step toward the goal of reducing the commercialization of human reproduction associated with transnational trade in human eggs is an increase in the domestic supply of human eggs. This can be achieved by means of the strategies outlined below.

\section{a. Clarify the law with respect to permissible reimbursements}

Section 7 of the AHR Act prohibits the purchase of gametes, and defines purchase in such a way as to capture all manner of exchange and indirect compensation. Section 12 limits reimbursement for the donation of gametes to receipted expenditures:

7. (1) No person shall purchase, offer to purchase or advertise for the purchase of sperm or ova from a donor or a person acting on behalf of a donor...

(4) In this section, "purchase" or "sell" includes to acquire or dispose of in exchange for property or services.

12. (1) No person shall, except in accordance with the regulations, (a) reimburse a donor for an expenditure incurred in the course of donating sperm or an ovum; $\cdots$

(2) No person shall reimburse an expenditure referred to in subsection (1) unless a receipt is provided to that person for the expenditure. 
It is important to note that while s. 7 is in force, $\mathrm{s} .12$ has not yet been brought into force. This is because the requisite regulations have not been drafted and passed (Baylis, Downie, and Snow 2014). As a result, at the present time, there is clarity with respect to the prohibition on purchasing eggs, and considerable uncertainty with respect to what is legally permitted in terms of reimbursements for expenditures incurred in the course of donating eggs (with or without receipts). We have argued elsewhere that, under the law as it is currently in force "no reimbursements are permitted until the regulations governing reimbursements are in force" (Downie and Baylis 2013, 235; Baylis, Downie, and Snow 2014). Others, including Health Canada, appear to disagree with us (Health Canada).

Regardless of who is right with respect to the meaning of the AHR Act and the AHR Reference, it is undeniably the case that there is considerable confusion and controversy over what the law is. This uncertainty with respect to reimbursements of expenditures might be having a chilling effect on egg donation. It is understandable that at least some women might be reluctant to donate where they will not be reimbursed for legitimate out-of-pocket expenses associated with providing eggs for others (including, for example, legal advice, transportation, dependent care, medications and counselling). It is also understandable that at least some fertility clinics and intended parents might be reluctant to provide reimbursements for costs to the egg donors if there is legal uncertainty about whether providing such reimbursement might land them in legal hot water. Clarity with respect to what expenditures are legally permissible could therefore increase willingness on the part of some women to donate. All that is required for there to be clarity is for Health Canada to draft regulations under s.12 of the AHR Act, for Parliament to pass those regulations, and for s.12 to be brought into force (Baylis, Downie, and Snow 2014). 


\section{b. Introduce changes to the law with respect to legal parentage}

The introduction and enforcement of better protections in law for egg donors could increase the supply of domestic donated eggs for third-party reproduction. The law has significant implications for child care and support, custody and access, names, and inheritance. Yet who are the parents when donor eggs have been used? Can a child have more than two parents? What steps, if any, are required to ensure that social parentage matches legal parentage? Currently, the law in many provinces as it relates to the assignment of legal parentage in the context of assisted human reproduction is unclear, confusing, or inconsistent with the intentions of many participants in assisted human reproduction. Furthermore, the law with respect to legal parentage varies across Canada.

To illustrate the confusing nature of the law in this arena, consider the fact that to determine the law with respect to legal parentage in a particular province or territory, one might have to review the following: Family Law Act, Vital Statistics Act, birth registration regulations, Child Status Act, and court cases. To illustrate the variability, consider the fact that the following approaches to legal parentage in the context of egg donation can be found: egg donors are not for that reason alone considered parents (PEI Child Status Act); step parent adoption may be required by intended mother where egg donor used (NWT Children's Law Act); parental declaration is available even where egg donor used (BC Family Law Act); parental declaration is not available where egg donor used (Yukon Children's Act); there can be only two parents (Alberta Family Law Act); and there can be more than two parents (Saskatchewan Children's Law Act).

Egg donors may rightly worry about the possibility that, as a result of operation of the law or their not understanding the law, they will find themselves without wanted parental rights 
or responsibilities or with unwanted parental responsibilities for offspring resulting from their egg donations. Clarifying the law can address the latter concern (misunderstanding) while law reform aimed at a legal parentage regime that protects egg donors can address the former. Together, both steps could increase the willingness of women to be egg donors.

\section{c. Introduce practice guidelines (or a broader legal regime) to protect and promote the health of egg donors}

Anecdotal evidence from investigative reporters (Blackwell 2012; Motluk 2010, 2012, 2013) and testimonials from women egg providers (Cool 2014; New Documentary 2010) suggest that some women have an incomplete understanding of the short- and long-term risks associated with egg production. Some women experience serious medical complications as a result of being overstimulated to maximize egg production, some women receive little or no follow-up medical care or counselling in dealing with psychological side effects, and some women are unable to get access to their (complete) medical records (Gruben 2013). This state of affairs is unacceptable.

In response to this status quo, Vanessa Gruben recommends, as appropriate, either guidelines or laws with the following content: (i) avoid and disclose real and perceived conflicts of interest; (ii) provide accurate and complete information to prospective egg providers and ensure that they fully understand the short- and long-term physical and psychological consequences of egg production; (iii) prevent the overstimulation of egg providers; (iv) maintain (and disclose to egg providers) complete and accurate medical records that include information about the screening process, the consent process, the stimulation protocol and any side-effects, the egg retrieval and any side-effect, and the number of eggs retrieved; (v) provide follow-up care for physical or psychological consequences, as needed (or ensure that such care is provided 
by another qualified physician or counsellor); and (vi) create an egg provider registry and mine the information therein to learn more about the health and safety of egg providers with particular attention to the short- and long-term physical and psychological risks associated with egg production. In this way, Gruben aims to better ensure that women who donate eggs for thirdparty reproduction receive proper medical care and psychological support.

We fully endorse these recommendations and believe that their implementation could go a long way toward protecting the health and well-being of egg donors. In turn, secure in the knowledge that protection and promotion of their health and well-being is a requirement, some women might be more inclined to consider altruistic egg donation.

\section{d. Elicit and respond to the concerns of experienced egg donors}

At this time there is very limited research on the views and values of Canadian egg donors. However, if one assumes that responding to the concerns of eggs donors might increase egg donation, at least one study suggests it might be worth exploring the merits of open-identity donation for those without a pre-existing familial or social relationship. As well, the establishment of a national personal health information registry to track the health information of donors and offspring might also increase egg donations (Blyth, Yee, and Tsang 2012). The matter of open-identity egg donation and the creation of a personal-health information registry is most certainly a provincial responsibility and so would require federal/provincial/territorial negotiations (AHR Reference 2010). 


\section{e. Develop and deliver targeted educational campaigns on altruistic egg donation}

Education is an obvious strategy to increase the number of egg donors. We do not, however, advocate educational campaigns that target the general population of women. We recognize that women in the general population may choose to become egg donors, but we are not committed to convincing women volunteers to put their health at risk for the benefit of others by becoming egg donors. Instead, we advocate educational campaigns that target groups of women in Canada who could donate eggs without incurring additional medical risks.

In Canada, as elsewhere, egg freezing is an option in a number of discrete circumstances including: "during the course of an IVF treatment, at the request of women whose fertility is threatened by disease or aggressive medical treatments (the so-called 'medical freezing') or at the request of women who fear infertility due to ageing (the so-called 'social freezing')" (Mertes et al. 2012). For a variety of reasons, many of the eggs stored by women for their own future reproductive use (or perhaps for their daughters' future reproductive use, as happens on occasion with the mothers of girls with Turner's syndrome) will never be used for this purpose and could be used for third-party reproduction. With eggs that are already in storage for future use, the rigours and risks of controlled ovarian hyperstimulation and egg retrieval have already been incurred by prospective donors in pursuit of their own (their family member's) reproductive goals.

Women in these different groups may not know that they can donate their eggs to others. Or, they may be aware of this option, but not fully appreciate the associated benefits (for the recipients and themselves). The primary benefit to recipients is that they may be able to achieve a pregnancy and bear a child. The primary benefit to donors is the profound sense of satisfaction known to accompany pure acts of altruism (Pennings et al. 2014; We Are Egg Donors). A 2007 
study of Canadian egg donors reports on the following possible rewarding aspects of egg donation: "being able to offer help; feeling value as an oocyte donor; knowing my donation helped the recipient couple alleviate the pain of infertility; knowing my donation resulted in a live birth and helped the recipient couples have a child; knowing my donation resulted in a successful conception; and knowing my donation helped the recipient couple to have a child" (Yee, Hitkari, and Greenblatt 2007, 2043).

Provincial/territorial governments (in consultation with clinicians from relevant specializations including reproductive medicine as well as psychology and social work) could develop and distribute appropriate, targeted educational materials and processes aimed at these three specific audiences. Such materials should be properly informative and the attendant processes should be non-coercive as the goal is to increase awareness and understanding, not to mislead or to coerce donation. Fertility clinics, for their part could assist with the distribution of educational materials and provide potential egg donors with orientation and counselling services.

To be clear, the goal is to increase egg donations, but not at the expense of free and informed choice. As such, while it will be important to inform prospective egg donors of the potential benefits to recipients and to themselves, it will be equally important to have them consider the potential emotional and psychological burdens of egg donation (Kenney and McGowan 2010) including most particularly the possibility of having one or more offspring 'out there in the world' that is/are genetically related to oneself, or being harmed by the sense of reproductive failure if donated eggs do not result in a live birth (Randall 2004). 


\section{Decreasing the domestic demand for domestic and foreign human eggs for third-party reproduction}

In pursuit of the goal of reducing the commercialization of human reproduction associated with transnational trade in human eggs, it is important to not only increase the domestic supply of eggs, but also to decrease the demand for domestic and foreign eggs.

\section{a. Programs and policies to prevent and treat infertility}

Fertility declines with age and population; studies suggest that the decline in women's fertility is quite steep by age 32 (Society of Obstetricians and Gynaecologists of Canada 2012). This decline is largely due to a decrease in the number and quality of eggs. In Canada, as in other high and middle-income countries, women delay childbearing because of educational pursuits, career goals, financial reasons, and later age of establishing committed relationships. Indeed, though from a biological perspective optimal child-bearing years are between the ages of 20 and 35, in Canada $11 \%$ of first births occur in women over the age of 35 (and some of these will have been made possible through the use of assisted human reproduction) (Society of Obstetricians and Gynaecologists of Canada 2012). Some women over the age of 35 who use IVF in an attempt to achieve a pregnancy will only be able to do so with the use of third-party eggs.

Thus, a first strategy to address a preventable cause of infertility and thereby decrease the demand for third-party eggs is to prevent social infertility due to natural ageing, and delayed reproduction. Not all women know that their fertility begins to decline in their 30 s, or know that certain lifestyle choices may affect infertility (such as cigarette smoking or heavy use of alcohol and some recreational drugs). As such, there are women who could benefit from fertility 
education programs that would allow them to make more informed reproductive choices (these choices might include earlier child-bearing or social egg freezing). This education could be provided by physicians and supplemented by web-based educational materials. Further, the provinces and territories could increase funding for improved parental leave and childcare services in an effort to begin to address the financial reasons for delayed childbearing.

A second strategy to decrease the demand for third-party eggs is to prevent (and where possible treat) medical infertility. Factors responsible for women's medical infertility include sexually transmitted infections or pelvic inflammatory disease, endometriosis or polycystic ovarian syndrome, unhealthy weight, environmental toxins, radiation, certain chemical and pesticides (Expert Panel 2009, 88). Some of these factors can be addressed through education (e.g., sexually transmitted diseases prevention programs for youth), but some require government action (e.g., policies to address environmental causes of infertility including exposure to lead, or exposure to certain agricultural or industrial chemicals). Governments, on the basis of public health considerations, could commit to evidence-based regulatory decision-making and undertake to ban (or significantly limit the use of) chemicals that cause, or are suspected of causing, infertility.

\section{b. Support child-free living as well as alternative ways of family-making (such as adoption)}

In tandem with efforts to prevent (and, where possible, treat) infertility, the provinces and territories could have policies to reduce the stigma of infertility, to legitimize and promote childfree living (whereby childlessness is not a disease that requires medical intervention), and to 
facilitate and promote alternative ways of family making. The latter could be done, for example, by providing better supports for adoption (public or private, domestic or international).

Current adoption processes are known to be complex and time consuming. Much could be done to streamline policies, standards and oversight for adoption services in an effort to facilitate the adoption of children who would otherwise remain in foster care or orphanages. Adoption would be an attractive family-making option for many if the structures, policies, laws, regulations and costs could be addressed.

Proponents of equal access to fertility treatments and adoption, Carolyn McLeod and Andrew Botterell, explain how current eligibility requirements and funding commitments make for unequal access (McLeod and Botterell 2014). Noteworthy, and in their view particularly egregious, differences in eligibility requirements are the mandated home study and parenting classes for adoption. As for the issue of funding, at least in those provinces that elect to fund or subsidize fertility treatment (funding in Quebec and Ontario; tax subsidies in Manitoba) there should be equivalent funding and subsidies for fertility treatment and for adoptions of all types.

\section{c. Develop and deliver a public awareness campaign on the harms of transnational trade}

A public awareness campaign on the legal and medical risks of transnational reproductive travel could be introduced as part of an effort to decrease the demand for human eggs in foreign countries.

We do not imagine that this public awareness campaign would be limited to reproductive issues, but rather would cover the gamut of medical interventions that people might seek abroad and would endeavour to draw helpful distinctions with respect to legal and medical risks between 
medical travel motivated by cost, long domestic waiting lists, goods or services that are unavailable because they are not yet proven safe and effective, and medical travel motivated by a desire to evade domestic law (Crozier and Baylis 2010). It must be noted here that this strategy could drive up the demand for domestic eggs and so place the two features of self-sufficiency outlined at the start of this article in tension. Here we would prioritize the reduction of exporting one's problems (i.e., not exporting commercialization) over the alignment of supply and demand. The public awareness campaign could also inform people of the legal and medical risks faced by egg providers so that those thinking about transnational trade are aware of the risks that their choice to purchase third-party eggs creates for egg providers. Related to this, another way to reduce demand could be to inform people of the socio-economic conditions under which many of the egg providers in other countries are living and the reasons for deciding to sell their eggs to support their family, put food on the table, pay their rent, pay tuition, or pay down loans (Cain-Nielsen 2013; Carney 2010; Talmadge 2013; New Documentary 2010).

Here we borrow an insight from Jennifer Parks in her writings on contract pregnancy where she insists that the buyers "must consider the kind of exploitative dynamic to which they are party, and the kinds of moral, social, and economic relationships they are constructing ... if one is going to engage in cross-border reproductive purchase and trade, one can be expected to be aware of the systems in place that allow wealthy countries [and individuals] such strong purchasing power in other nations" (Parks 2010, 336). Exposure to the socio-economic conditions might lead some prospective egg buyers to consider the transaction to be exploitative and to decide not to go through with it. The underlying assumption here is that if Canadians were familiar with the exploitative nature of the international market in human eggs, they might be less willing to engage. 


\section{d. Enforce the legal prohibition on purchasing eggs}

A final strategy for reducing demand would be to enforce the AHR Act prohibition on the purchase of eggs both domestically and transnationally. We have elsewhere argued for the qualified territorial application of the AHR Act to transactions partly occurring outside Canada (Downie and Baylis 2013). Meaningful enforcement could reduce the willingness of individuals to purchase eggs at home or abroad, and the willingness of clinicians to participate in the transnational trade in human eggs. As a reminder, s. 7 of the AHR Act stipulates that "No person shall purchase, offer to purchase or advertise for the purchase of sperm or ova from a donor or a person acting on behalf of a donor." Upon conviction, under ss. 60 and 62 of the AHR Act, these activities are punishable by a fine of up to 500,000 CDN or imprisonment up to ten years or both.

\section{Conclusion}

Prohibiting the buying of eggs in Canada appears to have encouraged some Canadians to go abroad to do what they are prohibited from doing at home. One way to counter this exporting of commercialization (and remain consistent with the $A H R A c t$ ) is to increase the domestic supply of donor eggs and decrease the domestic demand for eggs (whether sourced domestically or internationally) - that is, to pursue national altruistic self-sufficiency. In a previous article we called for national altruistic self-sufficiency in human eggs for third-party reproduction. In this article, we have briefly outlined a number of ways in which we could move closer to such selfsufficiency working within the boundaries of the AHR Act and thereby reducing the exporting of commercialization of human reproduction. It's the least we can do. 


\section{Acknowledgements}

Sincere thanks are owed to members of the NovelTechEthics research team for comments on a very early draft of this article. Thanks are also owed to two anonymous reviewers and to G.D.K. Crozier who provided comments on later drafts. Finally, Georgia Lloyd-Smith provided useful assistance with the references.

\section{Notes}

1. We use to the term egg donor to refer exclusively to women who gift their eggs. We use the broader term egg provider to refer to women who either gift or sell their eggs. On occasion, we quote others who (in our view, erroneously) refer to women who engage in commercial (as opposed to altruistic) transactions as egg donors. For our part, we are purposeful in our use of the term egg donor to only apply to women who do not receive payment for their eggs.

2. In our view, commercial trade in human eggs invites the exploitation of young women, especially those who are poor or otherwise vulnerable. Invariably women who sell their eggs whether in high, middle or low-income countries (for tens of thousands of dollars in high-income countries and hundreds of dollars in low-income countries) are dealing with buyers who are prepared to capitalize on their social, material and political inequality. As such, reducing transnational exploitation could be a valid reason for pursuing self-sufficiency in human eggs. We do not develop this line of argument in this article, however, as the reduction of transnational commercialization of reproduction motivates our commitment to self-sufficiency. 
3. A discussion of whether: (i) any or all requests for human eggs reflect only wants or desires, or whether some such requests reflect needs; and (ii) the meeting of only needs (or also wants and desires) should be permitted under the AHR Act is beyond the scope of this article.

4. In contrast, according to Crozier and Martin, the primary objective in pursuing selfsufficiency in human eggs is to "better meet needs within the domestic setting"; minimizing transnational trade in human eggs is a secondary objective (Crozier and Martin 2012, 49).

\section{References}

Assisted Human Reproduction Act, 2004 S.C., ch. 2 (Can).

Baylis, Françoise, Jocelyn Downie, and Dave Snow. 2014. Fake it 'till you Make it:

Policymaking and Assisted Human Reproduction in Canada. Journal of Obstetrics and Gynaecology Canada. 36 (6): 510-512.

Blackwell, Tom. 9 March 2012. Canada's Murky Legal World of Surrogate-Consultants and Human-Egg Buyers. National Post. http://news.nationalpost.com (accessed May 1, 2014).

Blyth, Eric. 2010. Fertility Patients' Experiences of Cross-Border Reproductive Care. Fertility \& Sterility. 94 (1): e11-e15.

Blyth, Eric, Samantha Yee, and Ka Tat Tsang, A. 2012. Perspectives of Canadian oocyte donors and recipients on donor compensation and the establishment of a personal health information registry. Journal of Obstetrics and Gynaecology Canada 34 (1): 72-79.

Cain-Nielsen, Kaye. 3 February 2013. Selling my eggs to make rent. Salon. http://www.salon.com/2013/02/03/selling_my_eggs_to_make_rent_partner (accessed May 1, 2014). 
Carney, Scott. September 2010. Unpacking the global human egg trade. Fast Company http://www.fastcompany.com/1676895/unpacking-global-human-egg-trade (accessed May 1, 2014.)

Child Status Act, 1988, S.P.E.I., c. C-6, s.9(6).

Children's Act, 2002, S.Y., c.13.

Children's Law Act, 1997, S.N.W.T., c.14.

Children's Law Act, 1997, S.S., c.C-8.2

Cool, Raquel. 6 January 2014. Crossing Borders: “Canada almost arrested me for allegedly selling my eggs." http://weareeggdonors.com/2014/01/06/canada-almost-arrested-me-forallegedly-selling-my-eggs/ (accessed May 1, 2014).

Crozier, G. K. D. and Dominique Martin. 2012. How to Address the Ethics of Reproductive Travel to Developing Countries: A Comparison of National Self-Sufficiency and Regulated Market Approaches. Developing World Bioethics 12: 45-54.

Crozier, G. K. D. and Françoise Baylis. 2010. The Ethical Physician Encounters International Medical Travel. Journal of Medical Ethics 36: 297-301.

Downie, Jocelyn and Françoise Baylis. 2013. Transnational Trade in Human Eggs: Law, Policy and (In)Action in Canada. Journal of Law, Medicine and Ethics 41 (1): 224-39.

Ethics Committee of the American Society for Reproductive Medicine. 2007. Financial compensation of oocyte donors. Fertility \& Sterility 88 (2): 305-309.

Expert Panel on Infertility and Adoption. 2009. Raising Expectations. Government of Ontario. http://www.children.gov.on.ca/htdocs/English/documents/infertility/RaisingExpectations English.pdf (accessed May 1, 2014).

Family Law Act, 2003, S.A. c.F-4.5. 
Family Law Act, 2011, S.B.C., c. 25.

Gruben, Vanessa. 2013. Women as Patients, Not Spare Parts: Examining the Relationship between the Physician and Women Egg Providers. Canadian Journal of Women and the Law 25: 249-83.

Health Canada. Prohibitions related to purchasing reproductive material and purchasing or selling in vitro embryos. Ottawa: Health Canada. http://www.hc-sc.gc.ca/dhpmps/brgtherap/legislation/reprod/purchasing-achat-eng.php (accessed May 1, 2014).

—. Prohibitions related to surrogacy. Ottawa: Health Canada. http://www.hc-sc.gc.ca/dhpmps/brgtherap/legislation/reprod/surrogacy-substitution-eng.php (accessed May 1, 2014).

Hughes, E and DeJean D. 2010. Cross-border fertility services in North America: A survey of Canadian and American providers. Fertility \& Sterility 94 (1): e16-e19.

Kenney, Nancy and McGowan, Michelle. 2010. Looking Back: Egg Donors' Retrospective Evaluations of their Motivations, Expectations, and Experiences during Their First Donation Cycle. Fertility \& Sterility 93 (2): 455-66.

Keown J. 1997. The gift of blood in Europe: an ethical defence of EC directive 89/381. Journal of Medical Ethics 23 (2): 96-100.

Kolata, Gina. 10 November 1991. Young women offer to sell their eggs to infertile couples. New York Times. http://www.nytimes.com/1991/11/10/us/young-women-offer-to-sell-theireggs-to-infertile-couples.html (accessed May 1, 2014).

Levine, Aaron D. 2010. Self-Regulation, Compensation, and the Ethical Recruitment of Oocyte Donors. Hastings Center Report 40 (2): 25-36.

Liebmann-Smith, Joan. 1992. Medical miracle ... or baby selling? Redbook 120, 124, 126. 
Martin, Dominique. 2010. Medical Travel and the Sale of Human Biological Materials: Suggestions for Ethical Policy Development. Global Social Policy 10: 377-95.

McLeod, Carolyn and Botterell, Andrew. 2014. "Raising Expectations about IVF but not Adoption". Impact Ethics, May 2014. http://impactethics.ca/2014/05/06/raisingexpectations-about-ivf-but-not-adoption/ (accessed May 6, 2014).

Mertes, Heidi, Guido Pennings, Wybo Donrop, and Guido de Wert. 2012. Implications of oocyte cryostorage for the practice of oocyte donation. Human Reproduction 27 (10): 2886-93.

Motluk, Alison. April 2010. The Human Egg Trade: How Canada's fertility laws are failing donors, doctors, and parents. The Walrus. http://thewalrus.ca/the-human-egg-trade/ (accessed May 1, 2014).

—. 19 February 2012. Wanted: Egg Donor in Good Health. CBC The Sunday Edition. http://www.cbc.ca/thesundayedition/documentaries/2012/02/19/wanted-egg-donor-ingood-health (accessed May 1, 2014).

—. 28 March 2013. "I Thought I Just Had to Sleep it Off”: Egg Donor Sues Toronto Fertility Doctor After Suffering Stroke. National Post. http://news.nationalpost.com/2013/03/28/kylee-gilman-sues-toronto-fertility-doctor/ (accessed May 1, 2014).

“New Documentary Eggsploitation Reveals the Infertility Industry’s Dirty Little Secret”. 2010. The Center for Bioethics and Culture. http://www.eggsploitation.com/pr.htm. (accessed May 1, 2014).

Parks, Jennifer. 2010. Care Ethics and the Global Practice of Commercial Surrogacy. Bioethics 24 (7): 333-40. 
Pennings, G., de Mouzon, J. Shenfields, F., et al. 2014. Socio-demographic and fertility-related characteristics and motivations of oocyte donors in eleven European countries. Human Reproduction 29 (5): 1076-89.

Randall, Asha Emsley. 2004. The Personal, Interpersonal, and Political Issues of Egg Donation. Journal of Obstetrics and Gynaecology Canada 26 (1): 1087-90.

Reference re Assisted Human Reproduction Act, 2010 SCC 61, [2010] 3 S.C.R. 457 (Can.).

Society of Obstetricians and Gynaecologists of Canada. 2012. Delayed Child-bearing:

Committee Opinion. Journal of Obstetrics and Gynaecology Canada. 34 (1): 80-93. http://sogc.org/wp-content/uploads/2013/01/gui271CO1201E.pdf.

Talmadge, Stephanie. 11 July 2013. College females turn to egg donations to fund school. USA Today. http://www.usatoday.com/story/news/nation/2013/07/11/egg-donations-fundingcollege-payments/2509997/ (accessed May 1, 2014).

van Aken, Willem Gerard, Council of Europe, Commission of the European Communities. 1993. The Collection and Use of Human Blood and Plasma in Europe: Report. Council of Europe Press.

We Are Egg Donors. http://weareeggdonors.com/ (accessed May 1, 2014).

World Egg Bank. 2014. Fee Schedule. http://www.theworldeggbank.com/fees.html (accessed May 1, 2014).

Yee, Samantha, Hitkari, Jason A., and Greenblatt, Ellen M. 2007. A follow-up study of women who donate oocytes to known recipient couples for altruistic reasons. Human Reproduction 22 (7): 2040-50. 